\title{
PELATIHAN VERIFIKASI PHOTO HOAX ATAU BUKAN DI MEDIA ONLINE DAN SOSIAL BAGI MAHASISWA IAIN TAKENGON
}

\author{
Muhammad Hasyimsyah Batubara ${ }^{1}$, Awal Kurnia Putra Nasution ${ }^{2}$, Mustafa Kamal \\ Nasution $^{3}$, Nurmalina ${ }^{4}$, Andika Hariyanto Surbakti ${ }^{5}$, Sungkawati Kardi Wahyuningsih ${ }^{6}$ \\ 1,2,3,4,5,6IAIN Takengon, Aceh Tengah, Aceh, Indonesia \\ email: muhammad.hasyimsyahbatubara@gmail.com ${ }^{1}$, awalkpn@gmail.com², \\ kamalnasution@gmail.com ${ }^{3}$, nurmalina125@gmail.com ${ }^{4}$, \\ andikahariyanto_surbakti@yahoo.com ${ }^{5}$, kardisungkawati@gmail.com ${ }^{6}$
}

\begin{abstract}
Information media and social media are part of the development of the latest civilization. Not infrequently, the information spread in it is false or hoax information. To detect the authenticity, the correctness of photos and information obtained on the network, efforts are needed to verify them properly. This PKM is carried out to train students about the importance of checking and rechecking photos and information in a network with search engine applications and identifying the origin of images and information. The PKM steps provide material presentations, lectures, discussions, and workshops. Attempts to verify this information can be done with Yandex, TinEye, Google, Duplichecker, Labnol, DuckDuckGo, Startpage, Bing. After this training, students are expected to be wise and intelligent in receiving information and further build and improve digital literacy intelligence as agents of change in civilization.
\end{abstract}

Keywords: Hoax, Media, Online, Training, Platform

\begin{abstract}
Abstrak: Media informasi dan media sosial bagian dari perkembangan peradapan terkini. Tidak jarang informasi yang tersebar didalamnya merupakan informasi palsu atau hoax. Untuk mendeteteksi keaslian maupun kebenaran photo dan informasi yang didapat di jaringan perlu usaha untuk memverifikasinya dengan baik. PKM ini dilakukan untuk memberikan pelatihan kepada mahasiswa tentang pentingnya cek dan ricek photo dan informasi dalam jaringan dengan aplikasi-aplikasi mesin pencari dan pengenal sumber asal gambar dan informasi. Adapun langkah-langkah PKM ini dengan memberikan pemaparan materi, ceramah, diskusi, dan workshop. Usaha memveripikasi informasi ini dapat dilakukan dengan aplikasi-aplikasi seperti Yandex, TinEye, Google, Duplichecker, Labnol, DuckDuckGo, Startpage, Bing. Setelah pelatihan ini mahasiswa diharapkan bijak dan cerdas dalam menerima informasi, dan lebih lanjut membangun dan meningkatkan kecerdasan literasi digital sebagai agen perubahan dalam peradapan.
\end{abstract}

Kata Kunci: Hoax, Media, Daring, Pelatihan, Aplikasi

\section{Pendahuluan}

Perkembangan media informasi daring dan media sosial di era teknologi sekarang memberikan ruang dan kesempatan kepada siapapun untuk membagikan berita, cerita maupun informasi kepada warga digital. Berita dan informasi beredar dan dibagikan secara massif dalam jaringan yang terkadang kebenarannya belum tentu sesuai kenyataaaan yang ada. Berita dan informasi ini belum tentu dapat dipertanggungjawabkan namun tidak jarang ditelan mentah-mentah oleh yang membaca dan melihatnya, dan lebih sial menjadi bagian dari yang membantu menyebarluaskan informasi palsu yang ia dapat ke orang lain. Berita palsu atau yang sekarang lebih trend namanya dengan kata hoax dapat diartikan sebagai sesuatu hal yang sengaja dilakukan dengan tujuan dan maksud untuk melakukan penipuan atau tipu muslihat guna mengambil keuntungan (WordNet, 2021). Sejarah kata hoax pertama dikenal di tahun 
1808 yang merujuk pada kata ratusan tahun sebelumnya yaitu prasa hocus pocus (Walsh, 2006 dalam Finneman, et al,. 2018). Namun, pendapat lain berkeyakinan kata hoax versi bahasa Inggrisnya dikenal dari tahun 1796 dan hubungan kata hoax dengan hocus sangat minim pembuktiannya (Harwood, 2005 dalam Finneman, et al,. 2018).

Lebih lanjut hoax juga dimaknai sebagai ketidakbenaran yang terencana dirancang untuk menyamar sebagai kebenaran, sehingga hoax yang diproduksi ini mempengaruhi opini publik (MacDougall, 1958 dalam Finneman, et al,. 2018). Pendapat lain menyebutkan bahwa hoax bukan tentang menghasilkan uang semata, namun hoax menyentuh sesuatu yang lebih dalam dan merupakan insentif kuat untuk membentuk opini publik dan untuk menarik perhatian publik (Boese, 2003 dalam Finneman, dkk,. 2018). Ahli lain juga membedakan makna kata hoax berbeda dengan makna penipuan, tujuan hoax adalah untuk dipublikasikan, sedangkan tujuan penipuan tidak untuk diketahui orang, para ahli telah mencapai beberapa konsensus tentang konsep tersebut, namun definisi yang disederhanakan tetap sulit dipahami (Walsh, 2006 dalam Finneman, dkk, 2018).

Cara memproduksi dan tujuan hoax bekerja yaitu dengan membujuk dan memanipulasi orang untuk melakukan atau mencegah reaksi yang telah ditetapkan sebelumnya, lazimnya memakai ancaman atau penipuan (Hernandez, et al., 2002). Penelitian terbaru juga mengidentifikasi model lain hoax seperti humor palsu atau satire atau parodi (Rubin,et al., 2015). Menurut Meinarni dan Iswara (2018) beberapa faktor yang berpotensi menjadi pemicu hoax atau berita bohong bisa karena alasan ideology, afiliasi politik, faktor ekonomi, dan popularitas. Indonesia sendiri menyikapi berita bohong sudah mengaturnya dalam hukum pidana Indonesia (KUHP) Pasal 390 KUHP yaitu mengenai fitnah, hinaan, hingga penyampaian laporan tertulis atau lisan palsu kepada pihak berwenang yang dapat mencemarkan nama baik orang lain. Dan lebih lanjut dengan aturan baru yang lebih spesifik dalam Undang-undang ITE pasal 28 ayat $1 \mathrm{UU}$ No. 11 Tahun 2008 (UU RI, 2008; Moeljanto, 2005).

Dari penjelasan diatas, dipandang perlu melakukan usaha dalam memberikan perspektif tentang hoax kepada mahasiswa dalam bentuk pendampingan. Dalam pengabdian masyarakat ini, kami akan memberikan wawasan dan cara untuk mendeteksi photo dan berita palsu yang tersebar di web dan media sosial. Photo dan berita yang ada di jaringan bisa di cek kapan dan siapa yang pertama kali memposting di jaringan. Sehingga kita dapat menilai apakah photo dan berita yang di posting sekarang ini merupakan photo dan informasi pertama dan terbaru atau malah informasi daur ulang yang pernah di bagikan oleh orang lain malah bertahun-tahun yang lalu. Usaha memverifikasi informasi ini dapat dilakukan dengan aplikasi-aplikasi yang tersedia.

Pada akhirnya harapan setelah pelatihan ini adalah membangun pandangan mahasiswa dalam menaggapi sesuatu informasi yang ia terima di media daring dengan bijak, dan bagian dari usaha untuk meningkatkan kecerdasan literasi digital mahasiswa sebagai agen perubahan dalam peradapan modren. Hal ini penting dilakukan supaya mahasiswa hadir sebagai benteng terhadap berita-berita palsu yang beredar, berseliweran 
Jurnal Pengabdian Masyarakat As-Salam (JPMA)

Vol. 1 No. 2 Juli - Desember 2021: 91 - 98

Muhammad Hasyimsyah Batubara, Awal Kurnia Putra Nasution, Mustafa Kamal Nasution, Nurmalina, Andika Hariyanto Surbakti, Sungkawati Kardi Wahyuningsih

dan bukan bagian dari masyarakat daring yang menyebarkan informasi palsu karena kurangnya usaha untuk cek dan ricek informasi.

\section{Metode}

Implementasi kegiatan pengabdian kepada masyarakat (PKM) ini sasarannya mahasiswa IAIN Takengon sebanyak 20 orang. Metode pelaksanaan dilalui dengan beberapa tahapan, yang pertama pembentukan tim pelaksana yang terdiri dari enam dosen dan dua mahasiswa sebagai anggota. Tahap berikutnya memberikan pelatihan sebagai prioritas solusi masalah dengan memberikan pemaparan materi, ceramah, diskusi, dan workshop. Tahap terakhir berupa review pelaksanaan kegiatan dan evaluasi serta merancang keberlanjutan program pelatihan.

\section{Hasil dan Pembahasan}

\section{Penggunaan Aplikasi Pendeteksi Sumber Asal Photo dan Berita}

Pada tahapan ini peserta diperkenalkan dengan beberapa platform yang dapat mendeteksi sumber asal sebuah photo dan informasi yang terdapat dalam jaringan. Aplikasi-aplikasi tersebut seperti dijelaskan dibawah ini.

1. Yandex https://yandex.com/images/

Situs Yandex merupakan mesin pencari yang berasal dari negara Rusia, digunakan untuk melakukan pencarian situs, foto dan video yang tidak bisa dicari menggunakan Google. Adapun langkah-langkah penggunannya di destop sebagai berikut:

a. Buka https://browser.yandex.com/

b. Pada halaman Yandex, klik tombol "Download".

c. Selanjutnya tekan tombol "Simpan Berkas".

d. Setelah unduh selesai, buka folder Download di Komputer Anda.

e. Tekan file "Yandex.exe" > tekan tombol "Run".

f. Kemudian silahkan lanjtkan prosesnya sampai selesai.

Untuk mengoperasikan Yandex Browser di Smartphone, silahkan melakukan pengunduhan di Google Play Store untuk Smartphone Android, dan di App Store untuk iOS (iPhone atau iPad).
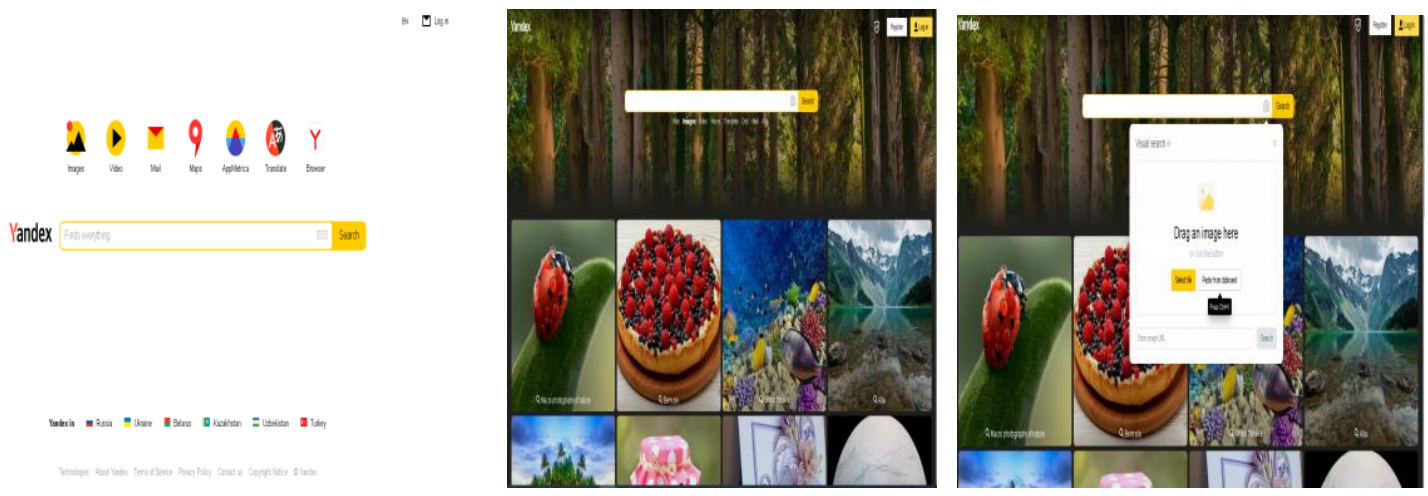

Gambar 1. Tampilan Yandex 


\section{TinEye}

https://tineye.com/

TinEye adalah perusahaan pencarian dan pengenalan gambar, dapat melakukan pencarian berdasarkan URL. Saat ini, indeks TinEye memiliki lebih dari 50,9 miliar gambar. Aapun cara mengunakanya baik itu dari komputer atau perangkat seluler dengan cara berikut.

a. Unggah gambar dari komputer atau perangkat seluler anda dengan mengeklik tombol unggah untuk menemukan gambar yang ingin anda cari.

b. Untuk mencari berdasarkan URL, salin dan tempel alamat URL gambar ke dalam kotak pencarian.

c. Seret gambar dari tab di browser Anda dan letakkan di tab browser tempat TinEye terbuka.

d. Salin dan tempel gambar dari papan klip Anda.

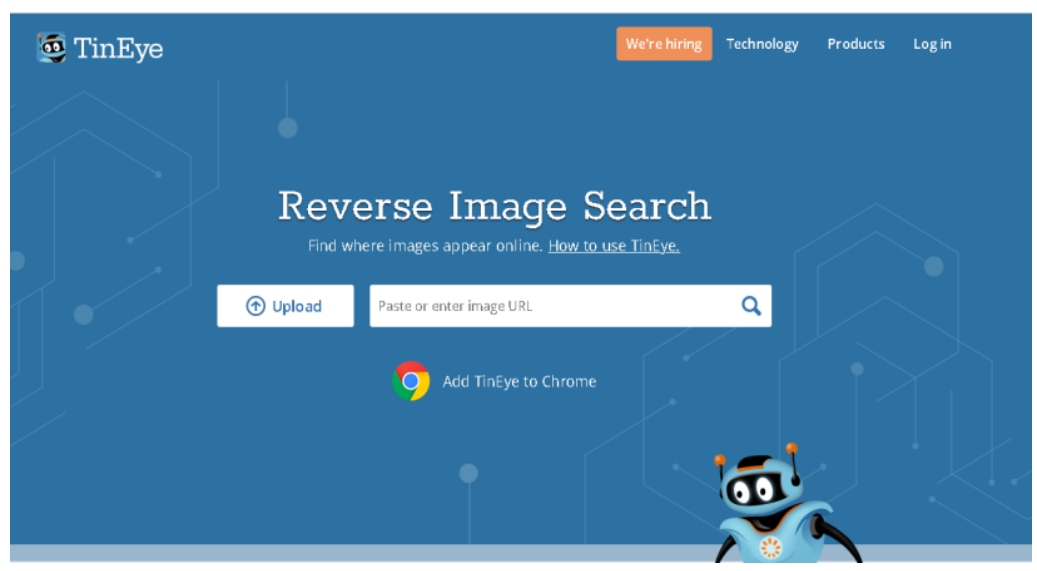

Gambar 2. Tampilan TinEye

\section{Google}

- https://www.google.com/imghp?hl=en

- https://chrome.google.com/webstore/detail/reveye-reverse-imagesear/keaaclcjhehbbapnphnmpiklalfhelgf?hl=id

\section{Google}

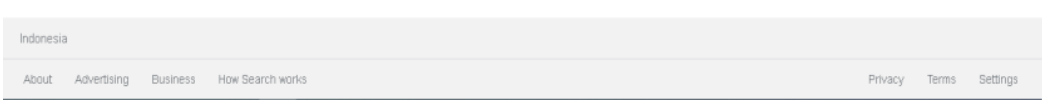

Gambar 3. Tampilan Google Image 
Jurnal Pengabdian Masyarakat As-Salam (JPMA)

Vol. 1 No. 2 Juli - Desember 2021: 91 - 98

Muhammad Hasyimsyah Batubara, Awal Kurnia Putra Nasution, Mustafa Kamal Nasution, Nurmalina, Andika Hariyanto Surbakti, Sungkawati Kardi Wahyuningsih

4. Duplichecker

https://www.duplichecker.com/reverse-image-search.php

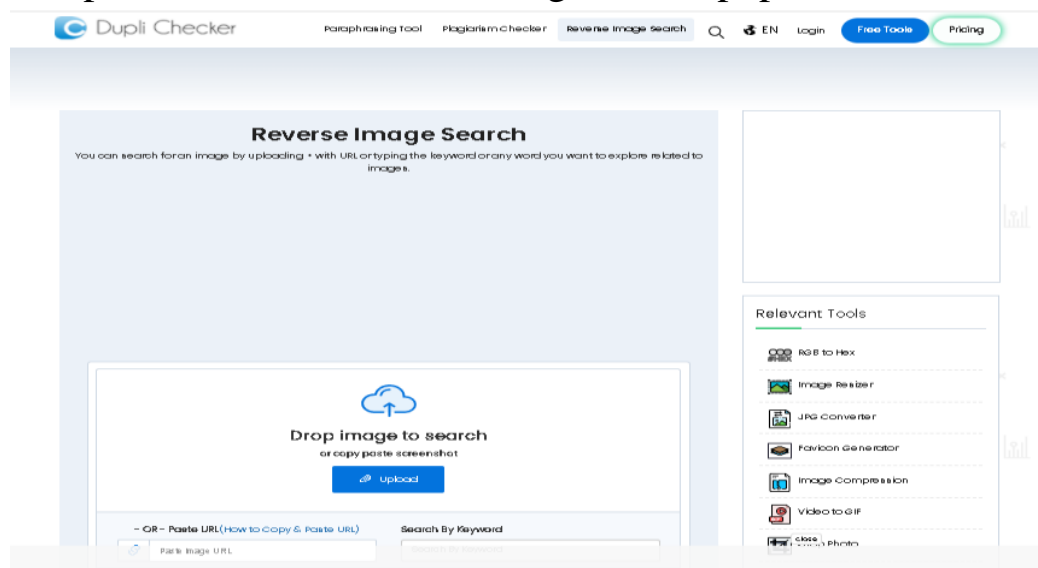

Gambar 4. Tampilan Duplichecker

5. Labnol

https://www.labnol.org/reverse/
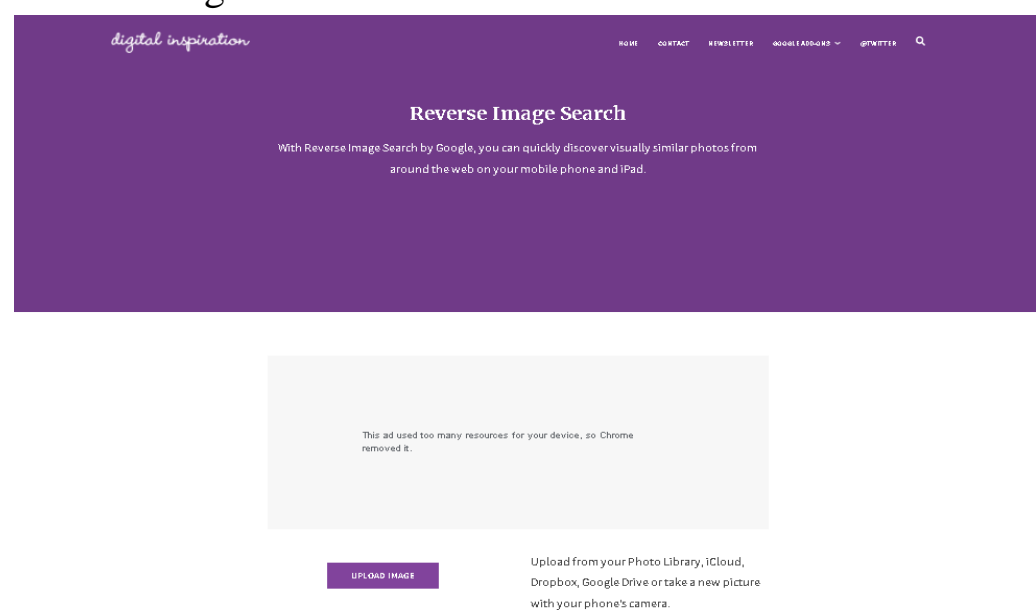

Gambar 5. Tampilan Labnol

6. DuckDuckGo

https://duckduckgo.com/

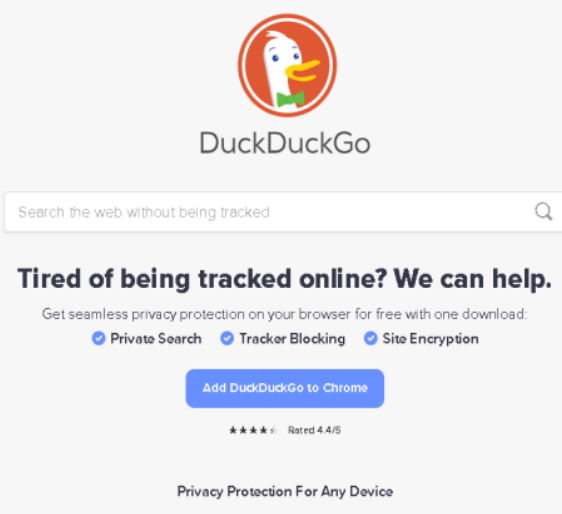

Gambar 6. Tampilan DuckDuckGo 
Vol. 1 No. 2 Juli - Desember 2021: 91 - 98

Muhammad Hasyimsyah Batubara, Awal Kurnia Putra Nasution, Mustafa Kamal Nasution, Nurmalina, Andika Hariyanto Surbakti, Sungkawati Kardi Wahyuningsih

\section{Startpage}

https://www.startpage.com/

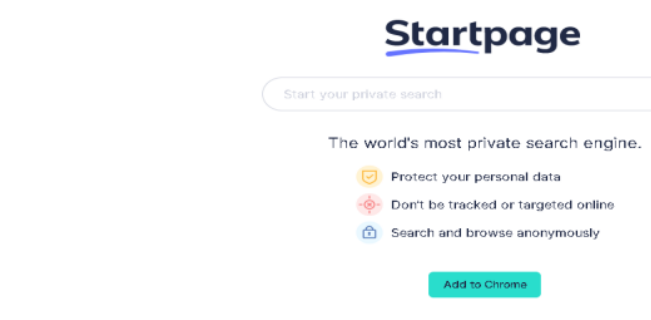

Gambar 7. Tampilan Startpage

8. Bing

https://www.bing.com/?scope=images\&nr=1\&FORM=NOFORM

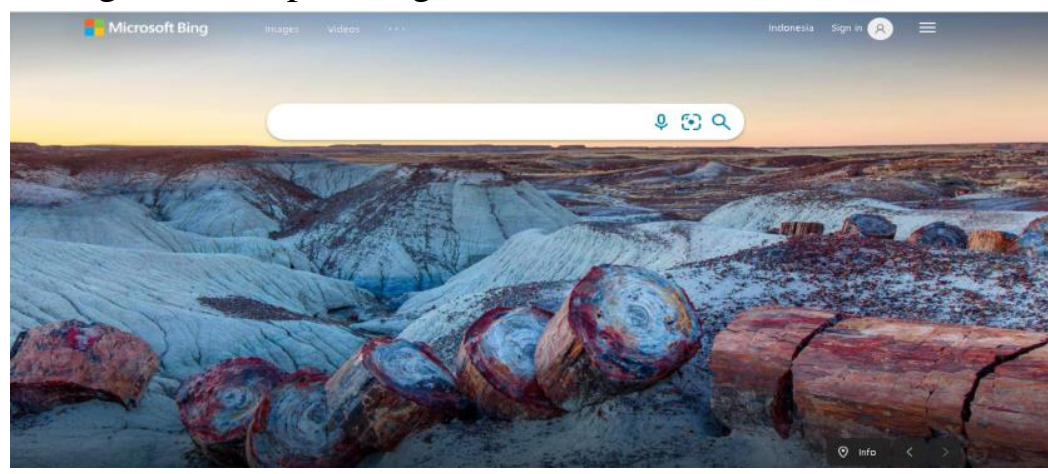

Gambar 8. Tampilan Bing

\section{Kegiatan Pelatihan Dan Diskusi Dengan Peserta PKM}

Pada fase kegiatan ini, para peserta tidak terlalu banyak bertanya karena penggunaan aplikasi-aplikasi yang diperkenalkan cukup mudah digunakan. Para peserta merasa terbuka wawasannya dengan PKM ini. Beberapa pendapat yang muncul menyatakan bahwa selama ini mereka sering mendapatkan photo lewat pesan WA dan cenderung selalu meyakini tentang photo yang mereka terima, namun setelah kegiatan ini mereka bisa terlebih dahu cek dan ricek keaslian photo sebelum menaruh keyakinan terhadap photo yang diterima.

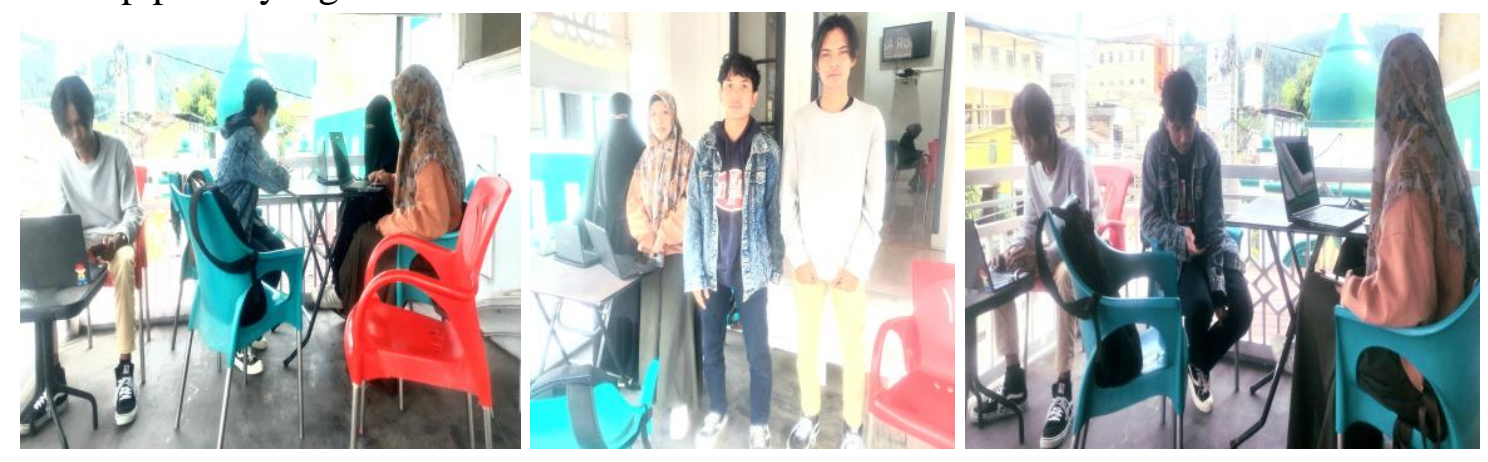

Gambar 9. Aktifitas Tanya Jawab Pada Pelatihan 
Jurnal Pengabdian Masyarakat As-Salam (JPMA)

Vol. 1 No. 2 Juli - Desember 2021: 91 - 98

Muhammad Hasyimsyah Batubara, Awal Kurnia Putra Nasution, Mustafa Kamal

Nasution, Nurmalina, Andika Hariyanto Surbakti, Sungkawati Kardi Wahyuningsih

\section{Kesimpulan}

Pelaksanaan PKM ini diharapkan membuka wawasan mahasiswa dalam literasi digital dalam era informasi yang serba digital. Hoax dan berita palsu bisa diredam dengan kemampuan mahasiswa untuk membentengi diri dengan memanfaatkan aplikasi-aplikasi yang tersedia untuk memverifikasi photo atau informasi yang mereka terima sebelum mempercayainya dan menyebarluaskannya. Mahasiswa yang ikut berpartispasi pada kegiatan ini diharapkan dan didorong untuk dapat menyebarluaskan ilmu yang didapat kepada mahasiswa lain.

\section{Ucapan Terima Kasih}

Pada kesempatan ini disampaikan terima kasih untuk segenap unsur yang terlibat dalam pelaksanaan pengabdian masyarakat ini, dan tidak lupa kepada pengelola jurnal pengabdian masyarakat As-Salam (JPMA) yang telah bersedia menyebarluaskan laporan kegiatan ini.

\section{Daftar Pustaka}

Boese, Alex.(2002). The Museum of Hoaxes. USA: Penguin Group.

Finneman, T., \& Thomas, R. J. (2018). A family of falsehoods: Deception, media hoaxes, and fake news. Newspaper Research Journal, 39(3), 350-361. https://doi.org/10.1177/0739532918796228

Harwood, Kenneth. (1958). Television Hoaxes Ahead. Television Quarterly, 36(1/2005), 51-54.

Hernandez, J. C., Hernández, C. J., Sierra, J. M., \& Ribagorda, A. (2002, October). A first step towards automatic hoax detection. In Proceedings. 36th Annual 2002 International Carnahan Conference on Security Technology (pp. 102-114). IEEE.

MacDougall, Curtis, D. (1958). Hoaxes, 2nd ed. New York: Dover Publications.

Meinarni, N. P. S., \& Iswara, I. B. A. I. (2018). Hoax and its mechanism in Indonesia. International Conference of Science Communication Research (ICCSR 2018), 183 186. https://doi.org/10.2991/iccsr-18.2018.39

Moeljatno. (2005). Kitab Undang-Undang Hukum Pidana (KUHP). Jakarta: Bumi Aksara.

Rubin, V. L., Chen, Y., \& Conroy, N. J. (2015). Deception detection for news: three types of fakes. Proceedings of the Association for Information Science and Technology, 52(1), 1-4.

https://doi.org/10.1002/pra2.2015.145052010083

Undang-Undang Republik Indonesia. (2008). Undang-Undang Republik Indonesia Nomor 11 Tahun 2008 tentang Informasi dan Transaksi Elektronik. Jakarta: Lembaran Negara Republik Indonesia Tahun 2008 Nomor 58.

Walsh, Lynda. (2006). Sins against Science: The Scientific Media Hoaxes of Poe, Twain, and Others. Albany: State University of New York Press.

WordNet Search. (20021). Hoax. Princeton, New Jersey: The Trustees of Princeton University.

http://wordnetweb.princeton.edu/perl/webwn?s=hoax\&sub=Search+WordNet\&o2=\&o0= $1 \& 08=1 \& 01=1 \& 07=\& 05=\& 09=\& 06=\& 03=\& 04=\& \mathrm{~h}=$ 
Vol. 1 No. 2 Juli - Desember 2021: 91 - 98

Muhammad Hasyimsyah Batubara, Awal Kurnia Putra Nasution, Mustafa Kamal Nasution, Nurmalina, Andika Hariyanto Surbakti, Sungkawati Kardi Wahyuningsih

https://yandex.com/images/

https://tineye.com/

https://www.google.com/imghp?hl=en

https://chrome.google.com/webstore/detail/reveye-reverse-imagesear/keaaclcjhehbbapnphnmpiklalfhelgf?hl=id

https://www.duplichecker.com/reverse-image-search.php

https://www.labnol.org/reverse/

https://duckduckgo.com/

https://www.startpage.com/

https://www.bing.com/?scope=images\&nr=1\&FORM=NOFORM 